New Domestic Vapour Bath.

Mr. Culverwell (the son of the druggist's fitting manufacturer) exhibited, at the last meeting of the Medical Society of London, a newly invented domestic vapour bath, an ingenious apparatus, which possesses the advantages of being very portable and easy to manage. It consists of a receptacle for water, or any medicated substance, which is heated by a spiritlamp; when hot, the vapour escapes from the sides of several little tubes, with flat, expanded tops, by means of which it is equally disseminated, instead of passing up in a single jet. There is also an elastic tube, which can be fixed to one of the flues in the top of the bath, the others being closed, by means of which vipour can be applied locally. The apparatus is neatly got up, and, we have no doubt, will answer well.

THE BIOGRAPHY OF SIR W. BURNETT. - ON THE CHLORIDE OF ZINC.

[NOTE FRONI MIR. NUNA.]

To the Editor of THE LANCET.

Sir,--In the Biography of Sir William Burnett, lately given in your journal, no mention is made of the value of chloride of zinc as an agent for the preservation of bodies for dissection.

All concerned in the study of anatomy have reason to feel grateful to the respected head of the medical department of the navy for the boon he has conferred upon them in the shape of a material having the property of retarding the decomposition of animal substances, without being in any way injurious to the individuals using it for that purpose, and especially for his giving them the means of protection against the poisonous influence of cadaveric matters.

I therefore hope that by giving insertion to this letter you will more fully make known the valuable qualities of Sir TVilliam Burnett's solution of chloride of zinc; and since abundant opportunities for forming an opinion as to its capabilities have been afforded me during the past five years, I do not hesitate to request the favour of a small space for the following particulars concerning its application:-

1. The "solution of the chloride of zinc" should be diluted with eight times its $b u l k$ of pure water.

2. The solution thus diluted is to be injected through the 2orta, until it begins to return by the veins.

3. When a coloured injection is to follow, twelve hours should elapse before such an injection is made.

4. When it is wished to preserve a part in a moist state, for any length of time, all fatty matters should be removed, and the part should be immersed in the solution, or should be wrapped in towels saturated with it.

5. For the hardening and preservation of the brain, the solution must by injected through the carotids.

6. During the warmer months the parts should be washed with strong brine, to destroy the maggots, the solution appearing too innocuous to these creatures.

7. It is necessary, before using soap for purification of the hands, or of cloths that may have been saturated with the solution, to wash away all the adherent chloride with plain water, otherwise the soap is decomposed, and a greasy stain is left behind.

The effect upon the various tissues is somewhat different; muscles become paler, and more or less brittle, but do not lose their other characteristics; ligaments and tendons preserve their distinctive sillkiness; adipose tissue is not protected from decomposition, the nerves retain their natural appearance; cellular membrane becomes opaque.

I am, Sir, your obedient servant

Middlesex Hospital, Nov. 25, 1850.

Thomas W. NunN, Demonstrator of Anatomy.

NOTE FROM MR. LIZARS, IN REPLY TO MR. SYME. To the Editor of The LaNceT.

StR,-A regard to the principle of "Audi alteram partem," I feel confident, will induce you to give a place in your columns to the following remarks, which I feel called upon to make in answer to Mr. James Syme's letter, which appeared in your number of the 16th inst. Without saying a word in reply, I might indeed remain satisfied that the animus which pervades the letter furnishes its own answer. Any one who can convert an important professional question into a subject of personal invective only betrays evidence of a bad temper elicited in a bad cause. With regard to the action of damages referred to by Mr. James Syme, a mind solely bent in the pursuit of scientific knowledge might perhaps have sought a different tribunal for its investigation than a court of law, in which I need scarcely remark that truth frequently constitutes libel. The decision of a court of law, where proof of the truth libelled is disallowed, affords no evidence of moral falsehood.

As to the appointment I formerly held, of Professor of Surgery to the Royal College of Surgeons here, the fact that I acquired that office by a majority of votes, in opposition to Mr. James Syme, an active but disappointed candidate, one would have thought would have prevented him alluding to it in the way he has done. This honour was the more gratifying to me, that it was conferred by the independent and unbought suffrages of my professional brethren, given upon an estimate of my qualifications, unaided by political intrigue or mercenary negotiation.

I have only further to state, that the communication which led Mr. James Syme to write the letter in question, and to which I refer, was written on public grounds entirely, and required facts, not abuse, for its refutation.

\section{JoHn Lizars,}

Late Professor of Surgery to the Royal College of Surgeons, and Senior Ope rating Surreon to the Royal Infir mary of Edinburgh.

Charlotte-square, Edinburgh, Nov. 20, 1850.

\section{ON A NEW THERAPEUTICAL AGENT-SOLUTION} OF PHOSPHATE OF QUININE AND IRON. To the Editor of THE LANCET.

SIR,-I have much pleasure in directing the attention of the profession to the therapeutical employment of a compound, formed by phosphoric acid, pure quina, and hydrated peroxide of iron-solution of phospliate of quinine and iron. It was devised by me during the past year, and from an extensive trial of it, since that time, I am enabled to recommend it as a remedy likely to prove highly serviceable in those cases indicating the use of such a combination.

As much uncertainty exists respecting the chemical relations of phosphoric acid, and the different bases, it is necessary to observe, that it is to the therapeutical and not the chemical value of this compound that $I$ attach importance.

I shall avail myself of the earliest opportunity of making further observations on the subject. I am, Six, yours, \&c., T. Catteli, M.D., M.R.C.S., \&c.

Braunston, Northamptonshire, Sept. 1850.

\section{AMMONIO-ACETAS FERRI AND SYRUPUS FERRI ACETATIS.}

To the Editor of THE LANCET.

SiR,-I have for some time used the above preparations of iron in my practice, and as I have found them to be very efficacious in cases where iron was required, I beg to lay the formulæ for their preparation before your readers. The syrup I consider to be well adapted for children; to adults I usually give them in combination.

I am, Sir, your obedient servant,

Croydon, Nov. 12, 1850 .

ALFRED ǴEO. ROPER.

Ammonio Acetas Ferri.-Dissolve one drachm of iron wire in half an ounce of hydrochloric acid, mixed with an equal quantity of water (by measure); then add half a gallon of water, and precipitate with five ounces of liquor potassw; set aside for twenty-four hours; draw off the supernatant liquor with a syphon; fill again with water, and repeat the process a third time. Lastly, collect the precipitate on a linen filter; dissolve the oxide thus prepared in two ounces of strong acetic acid, and make up the measure to ten ounces with distilled water; set aside for twenty-four hours, and filter. To every twenty ounces of the filtered liquor add half a drachm of strong liquor ammoriæ. Dose, ten minims to half a drachm. Syrupus Ferri Acetatis.-Dissolve two pounds of sugar in ten ounces of water, in a water bath; to the syrup, whilst hot, add eleven ounces of the acetate of iron, prepared as above (without the ammonia); when cold filter through paper. Dose, twenty minims to one drachm.

Dr. Rowland has been elected Assistant-Physician to the Charing-cross Hospital. 